\title{
DISTANCE LEARNING AND INTERACTIVE METHODS OF TEACHING UKRAINIAN AS A FOREIGN LANGUAGE
}

\author{
Olga Nastenko ${ }^{1}$, Igor Chornyi ${ }^{2}$, Nataliia Khanykina ${ }^{3}$ \\ ${ }^{1}$ Teacher, Bukovinian State Medical University, Chernivtsi, Ukraine, e-mail: olganastenko111@gmail.com, \\ ORCID: https://orcid.org/0000-0001-8381-9078 \\ ${ }^{2}$ Doctor of Philology, Professor, Kharkiv National University of Internal Affairs, Kharkiv, Ukraine, e-mail: \\ igorchornyi64@gmail.com, ORCID: https://orcid.org/0000-0001-6079-1746 \\ ${ }^{3}$ Senior Researcher, Candidate of Philology, Borys Grinchenko Kyiv University, Kyiv, Ukraine, e-mail: \\ nayka.diss@i.ua, ORCID: https://orcid.org/0000-0002-5920-9779
}

\begin{abstract}
The proposed academic paper considers the features of distance learning and interactive methods of teaching Ukrainian as a foreign language, namely the basic concepts, models of learning, the specifics of the practical use of online methods in today's conditions. The purpose of the academic paper was to analyze the specific features of distance learning and interactive methods of teaching Ukrainian as a foreign language in a modern educational environment. The content of the concepts of "distance learning" and "interactive teaching methods" has been investigated by the methods of comparative analysis and synthesis; the specifics of distance learning in the modern educational environment have been characterized; the method of classification of interactive teaching methods has been applied in order to identify the most effective ones in teaching Ukrainian as a foreign language. In order to optimize distance learning of Ukrainian as a foreign language, a method of creating a virtual learning environment is proposed. The offered model will provide an opportunity to form a flexible structure of the educational environment for learning Ukrainian as a foreign language in different conditions, which will improve the quality of distance learning and guarantee high knowledge of students.

Keywords: educational environment, distance learning, interactive methods, educational platforms, digital age.
\end{abstract}

JEL Classification: I24, I29

Formulas: 0; fig.: 0; tabl.: 0; bibl.: 15

Introduction. Force majeure circumstances that have occurred in the world, contributed to the accelerated modernization of the forms of education, the development of an integration complex of teaching methods and, as a result, the emergence of the term "online learning", which should be understood as an improved form of distance learning, namely: use of Power Point presentations, testing programs and development of e-courses on different platforms as a single integration model. In the learning process, there was an expansion of the functions of online learning as a tool of the educational process, which allowed teachers to take into account the different levels of knowledge of students when conducting webinars, focusing on the results achieved by students on educational platforms.

Thus, it can be said that there is a change in priorities when assessing the role of online learning in the educational process. Online learning ceases to play a supporting role and gradually begins to play a leading role in the modern education system.

Another important task of distance learning is to maintain and increase students' motivation to learn in the current situation. In order to implement this, we propose optimization of work when using existing educational platforms with students on remote learning. 
In the conditions of the information society, along with traditional forms of education, modern methods based on technologies such as distance learning with the use of webinars, focused on the individual needs of the student and the level of his knowledge, are increasingly being used. This makes it possible to make the educational process more flexible, universal and personality-oriented. With the development of information technology and local networks, new learning opportunities have emerged that allow maintaining the educational process at the appropriate level.

Literary Review. The investigation, improvement of online learning methods, in particular when studying Ukrainian as a foreign language, is an urgent topic of modern methodologists and researchers. Researches of Luis Miguel Dos Santos are aimed at finding optimal and effective teaching methods and strategies as an integral part of the process of learning foreign languages (Luis Miguel Dos Santos, 2020). The specificity of the modern educational process is the widespread introduction of online learning with application of a variety of techniques. Reni Puspitasari Dwi Lestariyana and Handoyo Puji Widodo note that currently the educational environment is part of the global digital age, and students are active users of modern digital technologies through the use of resources such as Facebook, Instagram, blogs and WhatsApp (Reni Puspitasari Dwi Lestariyana, 2018). The online environment is becoming a common, mandatory element of modern youth life.

From this point of view, distance learning in general, and, the use of interactive methods in the study of Ukrainian as a foreign language, in particular, is a topical issue in the field of view of numerous researchers. Investigations of Matthew Murdoch substantiate the emergence of the educational process based on the use of interactive learning technologies (Matthew Murdoch, 2019). This type of training is an affordable means of disseminating ideas, innovations and education in the world. The existing variety of options for searching for information, according to the researcher's viewpoint, not only stimulated the movement of the explosive wave of learning in the direction of virtual classrooms and other similar online learning platforms, but also provided a kind of dawn of the modern educational environment.

Nowadays, there is a continuous improvement of interactive distance learning methods. According to Bowen and William G., the introduction of online learning has led to significant improvements in the academic infrastructure and, as a result, has saved time in obtaining new information.

N.P. L. Nariyati, Sudirman, N.P.A. Pratiw pay attention to the rapid changes of the learning process; the scholars point out that mobile strategies play a significant role in the digital age, allowing continuous improvement of the learning process (N.P L. Nariyati, Sudirman, N.P.A. Pratiw, 2020)

Chartrand R. argues that modern technology opens unlimited access to educational materials to anyone (Chartrand R., 2020). This fact greatly facilitates the educational process and makes it accessible to a wide range of people.

The opinion of Nadıran Tanyeli (Nadıran Tanyeli, 2009) lies in the fact that the use of the Internet as a learning tool will turn the learning process into an interesting process, and, above all, for those who learn a foreign language. 
Currently, the impact of new forms of learning on students' motivation to learn is also being investigated. Muhammad Dafit Pitoyo, Sumardi Abdul Asib point out that there is a tendency to reduce the role of traditional forms of learning in the 21st century (Muhammad Dafit Pitoyo, Sumardi Abdul Asib, 2020). In their study, the authors showed that students increased motivation to learn, they began to learn more intensively after passing game tests on the free learning platform Quizizz.

Distance education involves the implementation through the introduction of educational technologies, mainly with the use of information and telecommunications technologies with indirect (at a distance) or fully indirect interaction of the learner and the teacher (Schlosser, L.A.; Simonson, M.R.; Hudgins, T.L., 2010).

According to Hillary Perraton's research, the learning process, during which most of the teaching time is conducted by someone on a remote basis (a teacher, a tutor) in space and (or) time from students, should be considered as distance education (Perraton, H., 1988). Investigating the structure of the distance learning process, Greenville Rumble (1989) has noted that the necessary elements are as follows: a teacher, one or more students, a course or curriculum, a contract between a student and a teacher, or an educational institution where a teacher works. A characteristic feature of distance education, according to the viewpoint of G. Rumble is the physical distance between a student and a teacher, which involves the use of additional technical means of learning (Rumble, G., 1989).

Aims. The purpose of the academic paper is to analyze the specific features of distance learning and interactive methods of teaching Ukrainian as a foreign language in a modern educational environment.

Methods. The content of the concepts of "distance learning" and "interactive teaching methods" has been investigated by the methods of comparative analysis and synthesis; the specifics of distance learning in the modern educational environment have been characterized; the method of classification of interactive teaching methods has been applied in order to identify the most effective ones in teaching Ukrainian as a foreign language.

Results. Currently, distance learning has taken a leading position in the effectiveness of conducting classes, in particular, in the conditions of forced isolation of students and teachers. Distance learning of Ukrainian as a foreign language makes it possible to effectively supplement learning in an offline format. Comparing classroom classes in offline and online format, it can be argued that these methods of learning, significantly different from the flexibility of the learning schedule; they give an unconditional advantage to distance learning. The unconditional advantages of distance education are the opportunity for the student to work at a time convenient for him and to repeatedly process the material if necessary. The traditional organization of the educational process according to a constant schedule does not provide the student with all the benefits of distance education. Thus, classes organized on a realtime schedule differ by the remoteness of students, but on the other hand, the organization of the educational process in a distance format significantly transforms the role of the teacher. In particular, special requirements may be put forward to the teacher, namely: the ability to use ICT tools (information and communication 
technologies). From another point of view, the introduction of distance learning requires competence (the ability to use distance technologies) not only by the teacher but also by those who learn. According to the viewpoint of M.N. Evstigneev, ICT competence of a teacher is a certain construct consisting of theoretical knowledge about modern information and communication technologies and practical skills of creation and use of educational Internet resources, social services Web 2.0 and other ICT technologies in the process of formation of language skills and development of language skills during foreign language learning and culture of the country of the studied language (Evstigneev, 2011).

The current situation, prevailing in education, shows that it has become vital to conduct classes using new information technologies. It should be noted that the introduction of online learning in the educational process should not exclude traditional teaching methods, but only complement them. The main purpose of online learning is the formation of sustainable motivation through the active participation of students and teachers in the learning process. It is possible to provide qualitative improvement of results of educational activity only at a reasonable combination of the accumulated methods, personal experience and modern technologies. The benefits of online learning are as follows:

- the possibility of differentiated and individual learning for all students (including those with disabilities, territorial accessibility of education);

- interactivity;

- quality of tests;

- instruction by means of showing objects;

- justification of the use of audio and video materials;

- the possibility of using this type of training to work with gifted students;

- remote participation in competitions, contests, conferences.

The main innovative qualities of online learning include the following ones:

- providing all components of the educational process: obtaining information, practical classes, assessment (control of educational achievements);

- interactivity, which provides a sharp expansion of opportunities for independent learning through the use of active forms of learning;

- the possibility of more full-fledged learning outside the classroom.

The emphasis on fullness is not accidental. This is not about finding and retrieving textual information from remote sources. Completeness in this case is considered as the implementation outside the classroom of such types of educational activities that previously could only be performed at school, namely: the study of new material on a subject basis, current control of knowledge with assessment and conclusions, preparation for exams, and much more, including collective educational work of remote users.

The teaching method is understood as a didactic category; it gives a theoretical idea of the system of norms of interaction between a teacher and a student in order to achieve common learning goals. The main idea of the online learning methodology is to create a virtual learning environment that includes various online sources, conducting online classes and consultations, developing testing. The constituent parts 
of online learning are students and teaching staff, whose interaction is carried out using modern telecommunication means. An important integrated factor of the distance learning system is a set of pedagogical methods and techniques used in the learning process.

These are, first of all, interactive databases; electronic magazines; computer training programs (electronic textbooks, grammar trainers). A special role in online learning is played by web conferences, allowing all participants to lead an active polylogue, which has great didactic value.

We suggest using a comprehensive approach to teaching the Ukrainian language, forasmuch as it is impossible to test all the competencies of students with one resource.

It is best to use the ZOOM online platform to practice speaking and listening skills. This platform provides the widest opportunities in the organization of a video lesson, namely:

- the ability to see the student (the organizer has the opportunity to turn on the listener's video);

- to divide the group into subgroups in order to practice dialogues, monologues;

- to use a "virtual" board;

- to demonstrate the teacher's laptop screen;

- to send files to students;

- to organize chats for students.

On the above-mentioned platform, "classroom" classes are held, including such methods of work as polls, monologue, and conversation. During the lesson, students have the opportunity to ask questions to the teacher directly.

Based on the text library of mini-texts presented in the course, students must create a monologue in writing, where they need to identify the intentions laid down in the text written by them (for example, to give a recommendation, describe a person, etc.). Also, when writing a monologue, students must use lexical and grammatical tools of different functional styles of the language. The results of the work are also discussed in a webinar with the teacher and other students.

The proposed method of online learning makes it possible to ensure the quality of the subjects studied in any complex situation (for example, during a pandemic). As advantages of this method of training it is possible to note the following ones, namely: mobility; versatility; the possibility of educating children with disabilities; possibility of multiple viewing of classes and webinars.

Among the disadvantages of online learning, the following ones should be mentioned, namely: lack of direct communication between a teacher and a student; students' workload with increased homework; the need for strict adherence to the schedule; need to have a laptop and high speed internet.

Modernity dictates its rules in all spheres of activity. It must be recognized that distance education or online learning is becoming a reality of higher education. However, it requires retraining of teaching staff, adjusting curricula, equipping universities with modern distance learning tools, involving IT professionals to create e-courses, journals, information and identification of the learners. 
Most of the methodologists share the point of view that the effectiveness of distance learning of Ukrainian as a foreign language should be based on a kind of construction of a virtual language environment formed by a complex of electronic educational, applied, instrumental and communication means. Such tools will provide full-fledged educational interaction between the subjects of the educational process (a teacher and a student) separated by a space-time continuum, with the help of interactive pedagogical technologies [Bogomolov 2004, p. 14].

The system of higher education in our country is moving towards the modernization of existing educational systems, intensive introduction of interactive learning technologies in the educational process. Modern conditions of teaching Ukrainian to foreign students require adherence to the technological approach in the implementation of distance learning. Distance courses for the study of the Ukrainian language by foreign students should contain a transparent structure, which includes the following structural and logical components, namely:

1) general information about the discipline being studied;

2) recommendations on the sequence and timing of studying the materials of the modules of the academic discipline;

3) general recommendations for the implementation of educational tasks (practical, independent) by students;

4) substantiation of criteria for assessment of knowledge, skills and abilities that the student will master during the study of the discipline;

5) theoretical material necessary to master the discipline of the credit-modular approach;

6) methodical recommendations on mastering independent material;

7) forms and terms of interactive interaction of students and a teacher during the semester;

8) a list of test tasks for testing and control of knowledge, skills and abilities of students in the process of studying the discipline (intermediate control);

9) examples of correct answers to all tasks to test the student's knowledge;

10) web resources and software needed to perform practical types of educational work;

11) a system of interactive communication between students.

The proposed structural elements form a single system that includes such blocks as: instructional, informational, communicative and control, which ensure its functioning.

The instructive block is the main one, which combines methodological recommendations for the study of the material and the requirements for control (current, final, semester).

The next block is the information one that forms the content of the instructional block. The components of the block are theoretical material and practical tasks (necessary for the formation of linguistic competence of students). This block involves acquainting students with the essence of the discipline being studied. 
The best option for the existence of a communicative block is to offer a forum where students have the opportunity to receive and discuss news of the course offline, and a chat created for online consultations.

The control block involves checking and assessing the level of language competence of foreign students. In order to introduce students with the grading system, they are asked to study in detail such an element of the course as the "Grading Scale", which includes a table and comments.

Distance learning is a modern reality, without which the education of the XXI century is inconceivable. However, it should be noted that it can only be part or supplement to the traditional form of learning of the modern student, but cannot replace it in $100 \%$.

Despite the popularity and general acceptance of this type of learning, it should be noted that online learning cannot replace "live" communication between a teacher and a student, completely replace the atmosphere of the academic environment, team and friendly communication between students; its task is only to supplement and expand the possibilities of classical learning.

Discussion. Investigating the problem of specific features of distance learning and interactive methods of teaching Ukrainian as a foreign language, we have considered the main approaches to the specifics of this process in today's educational environment. It should be noted that the existing approaches to the introduction of distance learning and interactive methods in teaching Ukrainian as a foreign language are quite diverse; consequently, they are constantly improving, and, accordingly, may be the subject of further research.

The modern educational process in the distance format is marked by the problem of unpreparedness of teachers for the skilled use of computer programs and services, as well as the ability to develop interactive resources for educational purposes.

When organizing the educational process in the context of remote practical classes according to the educational schedule, the teacher does not see each student with his own eyes, but interacts and controls with each student in an online lesson. The teacher (as it has been noted by most researchers on issues of distance learning) acts as a tutor-mentor who does not have to monitor the behavior of students when performing educational tasks; he can focus on providing educational material and control over the mastery of educational material by students. Speaking about the role of the teacher in the process of distance learning, it is worth giving preference to his mentoring functions, rather than regulatory ones.

In order to practice speaking and listening skills while learning Ukrainian as a foreign language in distance education, it is best to use the online platform ZOOM. This platform provides the widest opportunities in organizing a video lesson, namely: the opportunity to see the student (the organizer has the opportunity to turn on the listener's video); to divide the group into subgroups to practice dialogues, monologues; to use a "virtual" board; to demonstrate the teacher's laptop screen; to send files to students; to organize chats for students. On the above-mentioned platform, "classroom" classes are held, including such methods of work as polls, 
monologue, and conversation. During the lesson, students can ask questions to the teacher directly.

Conclusion. The current situation, prevailing in education, shows that it has become vital to conduct classes using new information technologies. Reasonable introduction of online learning in the educational process does not exclude traditional teaching methods, however, if possible, complements them. It is possible to provide qualitative improvement of results of educational activity only at a reasonable combination of the accumulated methods, personal experience and modern technologies. The advantages of online learning are the following features, namely: the possibility of differentiated and individual learning for all students (including those with disabilities, territorial accessibility of learning); interactivity; quality tests; clearness; justification for the use of audio and video materials; the possibility of using this type of training to work with gifted students; remote participation in competitions, contests, conferences.

The distance course of the Ukrainian language for foreign students helps meet the needs of distance learning. It also motivates foreign students of this form to gradually master the course materials; it significantly increases the efficiency of the learning process. The purpose of further research is to develop teaching and learning resources for distance learning, their introduction into the process of learning Ukrainian as a foreign language.

Thus, distance learning is a reality of our times, which can be used as an additional component of the traditional form of learning. Given the need for "live" communication between the teacher and the student, distance learning a foreign language in quarantine conditions should complement and expand the possibilities of classical learning.

Author contributions. The authors contributed equally.

Disclosure statement. The authors do not have any conflict of interest.

References:

1. Evstigneev M.N. The structure of ICT competence of a foreign language teacher // Language and culture. 2011. № 1. P. 119-125.

2. Prigozhin I. Philosophy of instability // Problems of Philosophy. — 1991. — № 6. — P. 46-52.

3. Foucault M. Words and things. Archeology of the Humanities / Transl from French of V.P. Vizgin and N.S. Avtonomova. - SPb.: A-cad, 1994. - 408 p.

4. Luis Miguel Dos Santos The Discussion of Communicative Language Teaching Approach in Language Classrooms // Journal of Education and e-Learning Research. 2020. Vol. 7. № 2. P. 104-109. ISSN(E) 24109991 / ISSN(P) 2518-0169. DOI: 10.20448/journal.509.2020.72.104.109

5. N.P.L. Nariyati, Sudirman, N.P.A. Pratiwi. EFL PRE-SERVICE TEACHER'S PERCEPTION TOWARD THE USE OF MOBILE ASSISTED LANGUAGE LEARNING IN TEACHING ENGLISH // International Journal of language Education. 2020. Vol. 4 № 1, March. P. 38 - 47. DOI: 10.26858/ijole.v4i2.10052

6. Nadiran Tanyeli. The efficiency of online English language instruction on students reading skills. World Conference on Educational Sciences 2009. Procedia Social and Behavioral Sciences 1 (2009) 564-567 1877-0428 C) 2009 Els evier Ltd. doi:10.1016/j.sbspro.2009.01.102 Open access under CC BY-NC-ND license.

7. Muhammad Dafit Pitoyo, Sumardi, \& Abdul Asib. Gamification-Based Assessment // The International Journal of language Education. 2020. Vol. 4. № 1, March. P. 1-10. DOI: 10.26858/ijole.v4i2.8188

8. Reni Puspitasari Dwi Lestariyana and Handoyo Puji Widodo. Engaging young learners of English with digital stories: Learning to mean [Electronic resource] // INDONESIAN JOURNAL OF APPLIED LINGUISTICS.Vol.

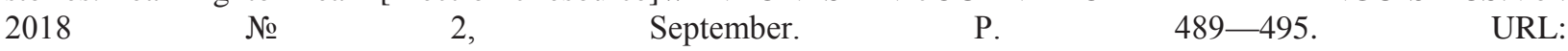
http://ejournal.upi.edu/index.php/IJAL/article/view/13314.doi:10.17509/ijal.v8i2.13314

9. Sanchez R.A., Hueros A.D. Motivational factors that influence the acceptance of Moodle using TAM // Computersin Human. Behavior. 2010. Vol. 26(6). P. 1632-1640. 
10. Schlosser, L.A.; Simonson, M.R.; Hudgins, T.L. Distance education: definitions and glossary of terms, Third edition. Charlotte, N.C.: IAP -Information Age Pub., 2010, P.1.

11. Machado M., Tao E. 2007. Blackboard vs. Moodle: Comparing User Experience of Learning Management Systems, in 37th ASEE/IEEE Frontiers in Education Conference, p. 7-12.

12. Suvorov R. Using Moodle in ESOL writing classes. TESL-EJ // The Electronic Journal for English as a Second language/ 2010. Vol. 14(2). P. 1-11.

13. Carolina Costaa, Helena Alvelosa, Leonor Teixeiraa. The use of Moodle e-learning platform: a study in a Portuguese University. CENTERIS 2012 Conference on ENTERprise Information Systems. 2212-0173 C 2012 Published by Elsevier Ltd. Selection and/or peer review under responsibility of CENTERIS/SCIKA Association for Promotion. and Dissemination of Scientific Knowledge. doi: 10.1016/j.protcy.2012.09.037

14. Perraton, H. (1988). A theory for distance education. In D. Sewart, D. Keegan, \& B. Holmberg (Eds.), Distance education: International perspectives. New York: Routledge, pp. 34-45.

15. Rumble, G. (1989). On defining distance education. The American Journal of Distance Education, \#3(2), pp.8-21

Received: April 14, 2021

Approved: May 20, 2021 